\title{
RACISMO: PROXIMIDADES E DISTANCIAMENTOS NAS PERCEPÇÕES DE ESTUDANTES E PROFESSORES
}

\author{
RACISM: PROXIMITIES AND DISTANCEMENTS IN THE PERCEPTIONS OF STUDENTS AND \\ TEACHERS
}
RACISMO: PROXIMIDADES Y DISTANCIAS EN LAS PERCEPCIONES DE ESTUDIANTES Y PROFESORES

\section{RACISME: PROXIMITÉS ET DISTANCES DANS LA PERCEPTION DES ÉTUDIANTS ET DES ENSEIGNANTS}

\author{
Victor Hugo Nedel Oliveira \\ Doutor em educação. Professor do departamento de humanidades pela CAp/UFRGS, Porto Alegre, RS- \\ Brasil. E-mail: victor.juventudes@gmail.com. \\ Orcid: http://orcid.org/0000-0001-5624-8476.
}

\begin{abstract}
RESUMO
Conhecer as percepções de estudantes e professores sobre distintos temas constitui-se de tarefa fundamental para proporcionar distintas interações no cenário da educação contemporânea. No Brasil, a temática do racismo constitui-se em dura e triste realidade social, cujas ações mancham a história do país, há muitos anos. O principal objetivo da investigação foi analisar as percepções de estudantes e professores de sétimo ano, de uma escola pública, em Porto Alegre (RS), em 2019, sobre o racismo. Para tanto, foi aplicado um questionário dividido em duas partes: a caracterização da amostra de investigação e a apresentação de seis afirmativas, pelas quais, a partir da escala Likert, os sujeitos deveriam afirmar seu grau de concordância, indiferença ou discordância. No questionário dos professores, ainda havia questão aberta, na qual os mesmos deveriam responder sobre as ações que realizam na busca de uma educação antirracista. Foi possível perceber que as proximidades nas percepções sobre o racismo entre estudantes e professores são maiores que os distanciamentos. Das seis frases apresentadas, em metade delas houve posturas de proximidade em relação aos sentidos atribuídos, e, na outra metade, foi possível perceber distanciamentos. Contudo, em uma análise mais detalhada, foi possível perceber que as proximidades superam os distanciamentos. Diversas ações para a promoção de uma educação antirracista foram citadas pelos professores, com destaque para debates, projetos literários e inclusão de personalidades negras. Dessa maneira, é possível considerar que, mesmo tratando-se de grupos com distanciamentos etários e sociais, as percepções sobre o racismo são diversas, mas próximas.
\end{abstract}

Palavras-chave: Racismo. Educação. Estudantes. Professores.

\section{ABSTRACT}

Knowing the perceptions of students and teachers on different themes is a fundamental task to provide different interactions in the contemporary education scenario. In Brazil, the theme of racism is a harsh and sad social reality, whose actions have stained the country's history for many years. The main objective of the investigation was to analyze the perceptions of seventh-year students and teachers, from a public school, in Porto Alegre (RS), in 2019, about racism. For this, a questionnaire divided into two parts was applied: the characterization of the research sample and the presentation of six statements, by which, based on the Likert scale, the subjects should affirm their degree of agreement, indifference or disagreement. In the teachers' questionnaire, there was still an open question, in which they should answer about the actions they take in the search for an anti-racist education. It was possible to perceive that the proximity in the perceptions about racism between students and teachers are greater than the distances. Of the six sentences presented, in half of them there were positions of proximity in relation to the assigned 
meanings, and in the other half, it was possible to perceive distances. However, in a more detailed analysis, it was possible to notice that the proximity exceeds the distance. Several actions to promote anti-racist education were mentioned by teachers, with emphasis on debates, literary projects and the inclusion of black personalities. Thus, it is possible to consider that, even in the case of groups with age and social distances, the perceptions about racism are diverse, but close.

Keywords: Racism. Education. Students. Teachers.

\section{RESUMEN}

Conocer las percepciones de estudiantes y profesores sobre diferentes temas es una tarea fundamental para proporcionar diferentes interacciones en el escenario de la educación contemporánea. En Brasil, el tema del racismo es una realidad social dura y triste, cuyas acciones han manchado la historia del país durante muchos años. El objetivo principal de la investigación fue analizar las percepciones de estudiantes y profesores de séptimo año, de una escuela pública, en Porto Alegre (RS), en 2019, sobre el racismo. Para ello, se aplicó un cuestionario dividido en dos partes: la caracterización de la muestra de investigación y la presentación de seis declaraciones, mediante las cuales, en base a la escala Likert, los sujetos deben afirmar su grado de acuerdo, indiferencia o desacuerdo. En el cuestionario de los docentes, todavía había una pregunta abierta, en la que debían responder sobre las acciones que toman en la búsqueda de una educación antirracista. Era posible percibir que la proximidad en las percepciones sobre el racismo entre estudiantes y maestros es mayor que las distancias. De las seis oraciones presentadas, en la mitad de ellas había posiciones de proximidad en relación con los significados asignados, y en la otra mitad, era posible percibir distancias. Sin embargo, en un análisis más detallado, fue posible notar que la proximidad excede la distancia. Los maestros mencionaron varias acciones para promover la educación antirracista, con énfasis en debates, proyectos literarios y la inclusión de personalidades negras. Por lo tanto, es posible considerar que, incluso en el caso de grupos con edades y distancias sociales, las percepciones sobre el racismo son diversas, pero cercanas.

Palabras clave: Racismo. Educación. Estudiantes. Profesores.

\section{RÉSUMÉ}

Connaître les perceptions des élèves et des enseignants sur différents thèmes est une tâche fondamentale pour fournir différentes interactions dans le scénario éducatif contemporain. Au Brésil, le thème du racisme est une réalité sociale dure et triste, dont les actions ont marqué l'histoire du pays pendant de nombreuses années. L'enquête avait pour principal objectif d'analyser les perceptions des élèves et des enseignants de septième année, d'une école publique de Porto Alegre (RS), en 2019, à propos du racisme. Pour cela, un questionnaire divisé en deux parties a été appliqué: la caractérisation de l'échantillon de recherche et la présentation de six énoncés, par lesquels, sur la base de l'échelle de Likert, les sujets devraient affirmer leur degré d'accord, d'indifférence ou de désaccord. Dans le questionnaire des enseignants, il y avait encore une question ouverte, à laquelle ils devaient répondre sur les actions qu'ils entreprennent dans la recherche d'une éducation antiraciste. Il a été possible de percevoir que la proximité dans les perceptions du racisme entre élèves et enseignants est supérieure aux distances. Sur les six phrases présentées, dans la moitié d'entre elles, il y avait des positions de proximité par rapport aux significations attribuées, et dans l'autre moitié, il était possible de percevoir des distances. Cependant, dans une analyse plus détaillée, il a été possible de remarquer que la proximité dépasse la distance. Plusieurs actions visant à promouvoir l'éducation antiraciste ont été mentionnées par les enseignants, l'accent étant mis sur les débats, les projets littéraires et l'inclusion de personnalités noires. Ainsi, il est possible de considérer que, même dans le cas de groupes d'âge et de distances sociales, les perceptions du racisme sont diverses, mais proches.

Mots-clés: Racisme. L'éducation. Étudiants. Enseignants. 


\section{INTRODUÇÃO}

Pensar os temas da educação em mundo contemporâneo e globalizado requer alguns câmbios de pensamentos, práticas e atitudes, pois, cada vez mais professores se dão conta da necessidade de melhor conhecer seus alunos e poder construir diálogos mais próximos e relações mais densas e que os atinja a ponto de colaborar na construção do conhecimento dentro e fora da sala de aula. Conhecer as percepções, pensamentos e opiniões dos estudantes, portanto, acerca dos mais variados temas e assuntos, trata-se de prática fundamental para o exercício pleno das múltiplas didáticas.

Nos contextos escolares, visualizam-se diferenças geracionais entre estudantes e professores, e os impactos dessas multiplicidades de pertencimentos nos mais diversos cenários de percepções sobre assuntos ordinários e da vida cotidiana. Trabalhos como os de Silva (1997) e Schmidt e Garcia (2005) já realizaram estudos comparativos entre as diferenças de percepções de estudantes sobre a violência na escola e a formação de consciência histórica, respectivamente. Oliveira (2019) já sinalizou, igualmente, a urgência de pesquisas que levem em conta um conhecimento sobre quem são os estudantes que se encontram nos bancos escolares, de maneira a que os docentes, por meio de seu planejamento pedagógico, conheçam melhor seus interlocutores, os estudantes.

O racismo constitui-se em uma prática extremamente violenta, abjeta e infame, mas que, infelizmente, forma parte da história do país, desde o momento da chegada dos escravizados africanos, passando pelos processos de abolição e nos períodos mais recentes de nossa história moderna e contemporânea. Seria possível imaginar o Brasil sem a presença das constantes ações racistas que assistimos, estarrecidos, cotidianamente? Oxalá a resposta dessa pergunta não se restrinja ao campo dos desejos ou dos sonhos e possamos viver em uma sociedade antirracista. Por outro lado, as políticas de ações afirmativas vieram e se instalaram de maneira a buscar, mesmo que parcialmente, reparar a dívida histórica que se tem com os negros no Brasil.

Estudos como os de Guimarães (2004), Hofbauer (2006) e Cerqueira e Moura (2014) já evidenciaram a importância de se pensar sobre as práticas de racismo no Brasil, a partir do preconceito de cor de pele e, ao mesmo tempo, sobre como as vidas de negros são perdidas a partir de atos de extrema violência racista. Ainda, apregoam a extrema relevância das políticas de ações afirmativas como potencial reparador histórico. 
Unindo e dialogando os eixos principais das percepções entre estudantes e professores sobre o racismo no Brasil, organizou-se a presente pesquisa, que visa estudar estas relações, a partir de um tempo e espaço específicos. Como o tema de pesquisa da presente investigação gira em torno das percepções de estudantes e professores sobre o racismo, há a necessidade de um recorte e uma delimitação, para que possa ser enquadrada como uma pesquisa do porte e dimensão a que se propôs.

No ano de 2019, em uma escola pública de Porto Alegre (RS), nos anos finais do ensino fundamental, em específico no $8^{\circ}$ ano, foram desenvolvidos trabalhos de iniciação científica, de maneira a que os estudantes pudessem compreender o método científico a partir de um caso real, com os padrões éticos, estéticos e políticos de uma pesquisa. Nesse sentido, o trabalho de Pires e Oliveira (2020), tratou da percepção sobre o racismo a partir da visão de jovens alunos da escola na qual a investigação foi desenvolvida e o trabalho de Almeida e Oliveira (2020), tratou das percepções sobre as percepções de racismo a partir da visão dos professores do grupo de alunos estudado na investigação anteriormente citada.

As justificativas que guiaram a realização da investigação, portanto, é a produção de novos conhecimentos a partir de pesquisas realizadas no âmbito da escola básica, ou seja, assume-se a escola enquanto espaço produtor de conhecimentos e não apenas reprodutor de conceitos e fórmulas experimentados unicamente pelo espaço acadêmico de nível superior. Igualmente, apregoa-se a necessidade de proporcionar a criação de conhecimentos que gerem uma melhor interação professor - alunos em relação ao tema do racismo, amplamente presente na sociedade. De todas as formas, muitos benefícios podem ser encontrados a partir de um levantamento de informações básicas sobre determinado grupo de estudantes e seus professores, a partir de uma temática recortada em particular.

A partir do que já fora exposto, utilizou-se da seguinte pergunta de pesquisa: "Como se aproximam ou se distanciam as percepções sobre racismo entre estudantes e professores de uma escola pública em Porto Alegre?".

O objetivo geral da pesquisa foi analisar as percepções de estudantes e professores sobre o racismo. Os objetivos específicos foram: caracterizar a amostra de pesquisa quanto aos aspectos sócio-econômico-culturais; verificar as percepções sobre 
racismo dos participantes da investigação; comparar as percepções sobre racismo entre estudantes e professores de uma escola pública de Porto Alegre (RS).

\section{Metodologia}

Ao quantificar os sujeitos da pesquisa, a investigação contou com a participação de um grupo de estudantes do $7^{\circ}$ ano do ensino fundamental de uma escola pública localizada na cidade de Porto Alegre (RS) e de seus respectivos professores. O universo da investigação no grupo dos alunos era composto por uma turma de $7^{\circ}$ ano do Ensino Fundamental com 30 estudantes. A amostra de investigação, desse grupo, foi composta por 30 sujeitos, com uma representatividade de 100\% do universo. O universo da investigação no grupo dos professores era composto pelo número de professores da turma de estudantes do sétimo ano, 15 professores. A amostra de investigação, do grupo dos professores, foi composta por 8 sujeitos, com uma representatividade de $54 \%$ do universo.

O local de realização deste estudo foi uma escola pública localizada na zona leste da cidade de Porto Alegre, no limite da capital do RS com o município de Viamão. Essa escola, quando da realização da pesquisa, atendia simultaneamente alunos do próprio bairro, bem como de bairros vizinhos e distantes e de outros municípios da Região Metropolitana de Porto Alegre e, em conjunção a outros dados é composta por estudantes de diferentes perfis socioeconomicoculturais. Quando do momento da coleta de dados a escola tinha cerca de 640 alunos matriculados, desde as séries iniciais do ensino fundamental, as séries finais do ensino fundamental, o ensino médio e a Educação de Jovens e Adultos.

O instrumento de coleta de dados foi um questionário (VIEIRA, 2009) estruturado e compartimentado em duas partes básicas. Na primeira, a caracterização da amostra de investigação, os participantes, tanto os sujeitos professores quanto os estudantes, foram convidados a responder sobre sua idade, identificação de gênero, etnia e local de residência. Para a tabulação desses dados, foram criados gráficos de colunas comparativos entre as respostas dos dois grupos de sujeitos participantes da investigação e, para fins estéticos, os dados dos estudantes foram representados na cor azul e os dos professores na cor vermelha. Na segunda parte, denominada "escala Likert", os sujeitos foram provocados, a partir de seis afirmações que apresentavam 
situações ou pensamentos relacionados ao racismo, e deveriam assinalar seu grau de concordância, indiferença ou discordância em relação à afirmação em tela. Para a tabulação desses dados, foram criados gráficos de barras, comparativos entre as respostas de estudantes e professores e, para fins estéticos e por padrão visual, repetiuse o esquema de cores utilizado nos gráficos da caracterização da amostra da investigação. No caso do questionário específico dos professores, foi acrescentada uma, no final, uma pergunta aberta que versava sobre as práticas que esses vinham promovendo em prol de uma educação antirracista.

A escala Likert (1932) trata-se de metodologia de amplamente utilizada para pesquisa de opinião, nas mais diversas áreas, pela qual é possível verificar o grau de concordância plena ou parcial, indiferença ou discordância plena ou parcial em relação a determinado tópico. Essa técnica é defendida por pesquisadores como Osinski e Bruno (1998) e Trojan e Sipraki (2015), quando evidenciam as categorias de respostas e as perspectivas de estudos comparados com o uso da escala Likert. Trabalhos como o de Oliveira, Lacerda e Santos (2019, 2020), já empregaram o uso de tal metodologia para captar as percepções de sujeitos de suas investigações sobre determinados tópicos a serem estudados e analisados, no campo da educação, obtendo resultados aceitáveis e possíveis de serem replicados em outras realidades.

Quanto à natureza, tratou-se de uma pesquisa aplicada Gil (2007), pois os conhecimentos produzidos a partir da investigação podem ser diretamente utilizados nos planejamentos e nas aulas ofertadas no espaço de pesquisa como poderão ser utilizados por outros professores ou pesquisadores que, porventura, tiverem acesso aos dados da investigação, em outras realidades. Quanto à abordagem, configurou-se como uma pesquisa quantitativo-qualitativa, visto que buscou trabalhar com dados numéricos e subjetivos, a partir da aplicação do instrumento de coleta de dados escolhido: questionário.

Quanto aos seus objetivos, tratou-se de uma pesquisa descritiva, pois procurou descrever as características de uma amostra específica (estudantes e professores), levantamento este que foi realizado através de instrumento próprio que descreveu a situação observada no momento da pesquisa. Em relação aos procedimentos técnicos, a investigação enquadra-se como um levantamento de uma amostra, já que houve a interrogação direta dos participantes da pesquisa em relação às suas percepções sobre o 
racismo, para, a partir de levantamento qualitativo, estabelecer relações entre os fatos analisados.

Em observância e atendimento às questões éticas na pesquisa, os participantes foram informados sobre os objetivos e o método da investigação, sobre o sigilo de seus dados e a possibilidade de deixarem de responder o questionário a qualquer momento.

Para fins de análise dos dados, as informações foram discutidas de forma associada. O material obtido foi submetido à análise de conteúdo proposta por Bardin (1977) para que se determinassem as percepções dos diferentes sujeitos acerca do racismo, envolvendo o levantamento das opiniões a partir de interpretação dos resultados por categorias temáticas, a partir das próprias afirmações que serviram de base para a coleta de dados. Os dados foram triangulados com das leituras realizadas, com as informações sobre a amostra de investigação e com as respostas das afirmações na escala Likert. Essa triangulação de dados Minayo (2005) nesse tipo de pesquisa é fundamental para a compreensão de fenômenos e contribui para a validade da proposta.

\section{Resultados}

Ao apresentar, para, posteriormente, analisar os dados coletados na investigação utiliza-se da divisão apresentada no instrumento de coleta de dados, ou seja, o questionário. Inicialmente, é realizada a apresentação da caracterização da amostra de pesquisa, com as informações de idade, gênero, etnia e local de residência dos sujeitos, em uma demonstração comparativa dos dados de estudantes e professores. Logo após, são apresentados e discutidos os graus de concordância em relação às frases apresentadas, nos dois grupos, ao serem expostos às afirmações sobre a temática do racismo.

Em um primeiro momento, apresentam-se os dados que compõem a caracterização da amostra da pesquisa, os quais permitiram reconhecer proximidades e distanciamentos nos perfis dos dois grupos dos sujeitos participantes da investigação: professores e estudantes.

Em relação à idade dos sujeitos da pesquisa, a partir da observação da figura 1, pode-se verificar que, entre o grupo de estudantes há um visível pico de participantes com 13 anos de idade (96\%), o que indica que esta maioria encontra-se em faixa etária 
escolar regular, visto que a investigação tratou de alunos vinculados ao $7^{\circ}$ ano do ensino fundamental, faixa esta justamente localizada na composição etária dos 13 anos de idade. Para além disto, localiza-se pequena disparidade para mais (4\% com 14 anos).

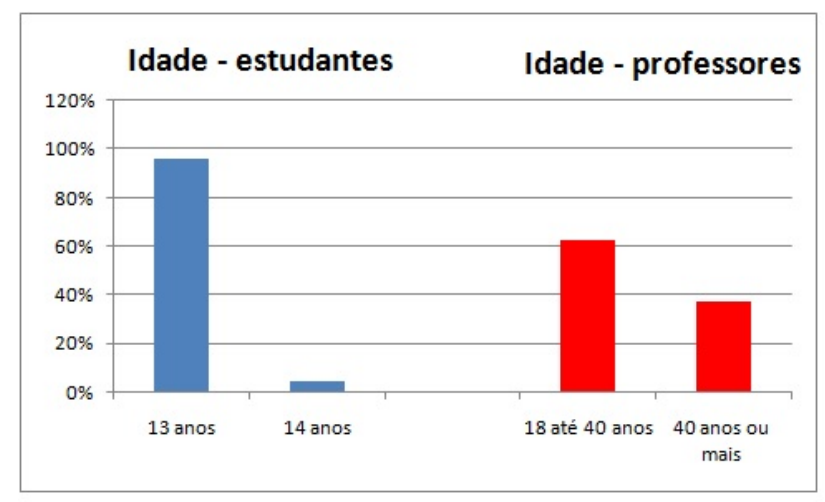

Figura 1: Gráfico - idade dos sujeitos

Organização: o autor (2020)

Sobre a idade dos sujeitos professores, é possível verificar que há uma maior porcentagem de participantes com entre 18 e 40 anos de idade (61\%). Para além disso, verificou-se o grupo com 40 anos ou mais (39\%). É possível considerar, portanto, que a maioria dos sujeitos estudantes encontrava-se na faixa dos 13 anos e que a maioria dos sujeitos professores encontrava-se na faixa dos 18 a 40 anos. Isso, por si só, já representa uma média de que a idade dos sujeitos variou, aproximadamente, em três vezes para mais, quando colocadas em comparativo.

Há uma divisão mais equitativa em relação ao gênero dos sujeitos da pesquisa, quando analisados os dados dos estudantes, como se pode observar na figura 2. Trata-se de $51 \%$ de participantes identificados ao gênero feminino e, consequentemente, $49 \%$ de participantes identificados ao gênero masculino. Desta forma, se encontraram poucas disparidades em relação a este tocante.

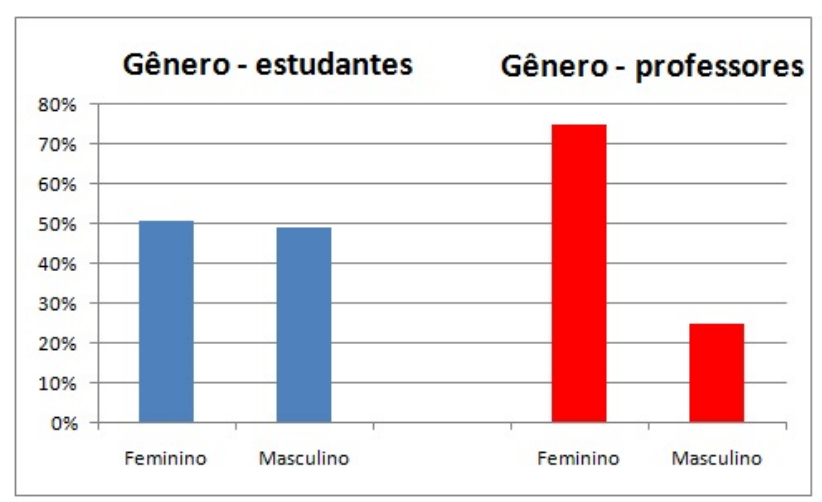

Figura 2: Gráfico - gênero dos sujeitos Organização: o autor (2020) 
Quando analisados os dados de gênero dos professores participantes do estudo, verifica-se que há uma tendência de disparidade, para mais, em relação aos identificados com o gênero feminino (75\%) em relação aos identificados com o gênero masculino (25\%). Ainda, foi possível constatar que, nem no caso dos estudantes, nem no caso dos professores, não houve identificação com outros gêneros que não os da expressão binária, masculino e feminino. Por fim, em relação ao tópico gênero, por mais que nos casos de estudantes e professores o gênero feminino tenha sido o mais expressivo dentre os participantes, foi no grupo dos professores que tal expressividade se acentuou.

Sobre as constatações em relação ao tópico etnia (figura 3), percebeu-se maior distribuição das mesmas ao analisar os dados dos estudantes, quando esses se apresentam com: $55 \%$ como brancos, $37 \%$ como negros e $8 \%$ como pardos. Ao relacionar, diretamente, o racismo com o tema da negritude no país, constata-se que a porcentagem de $45 \%$ dos estudantes compõe o número de negros e pardos nessa expressividade étnica.

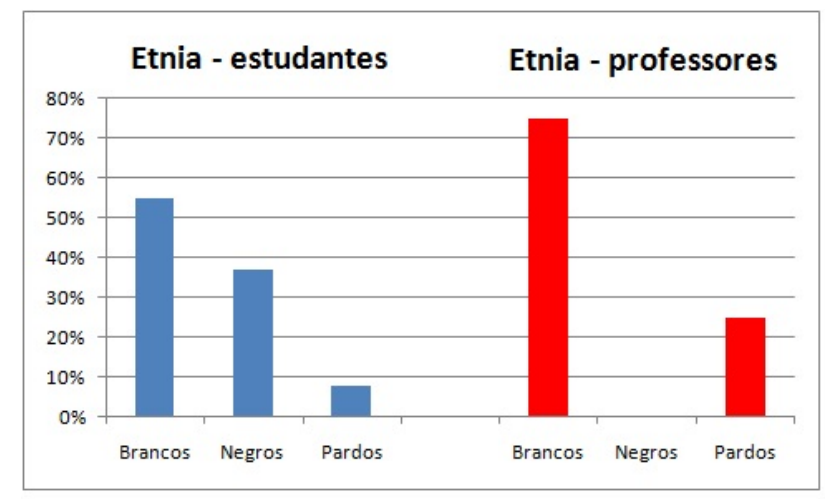

Figura 3: Gráfico - etnia dos sujeitos

Organização: o autor (2020)

Ao verificar os dados de autodeclaração étnica dos professores, foi possível perceber extrema discrepância em relação à distribuição encontrada nos dados dos alunos, pois $75 \%$ dos professores se autodeclararam brancos e $25 \%$ desses se autodeclararam pardos. Não houve nenhum professor que participou da investigação autodeclarado negro. Distintas e importantes discussões aqui poderiam ser empregadas, mas que, por si só, extrapolariam a discussão proposta no texto. O fato inegável é que, pelos dados encontrados, estudantes de escola pública tendem a ser maioria entre 
negros e pardos (45\%), em relação aos professores da mesma escola, cuja maioria (75\%) pertence à etnia branca.

Sobre os dados de local de residência dos sujeitos estudantes da pesquisa, foi possível verificar, conforme demonstrado na figura 4, que mais da metade (74\%) reside em Porto Alegre, capital do estado do Rio Grande do Sul, enquanto que 26\% residem em outras cidades, todas na Região Metropolitana de Porto Alegre, e a expressiva maioria desses em Viamão, município limítrofe com a capital e com a escola na qual estudam e que foi espaço da presente investigação.

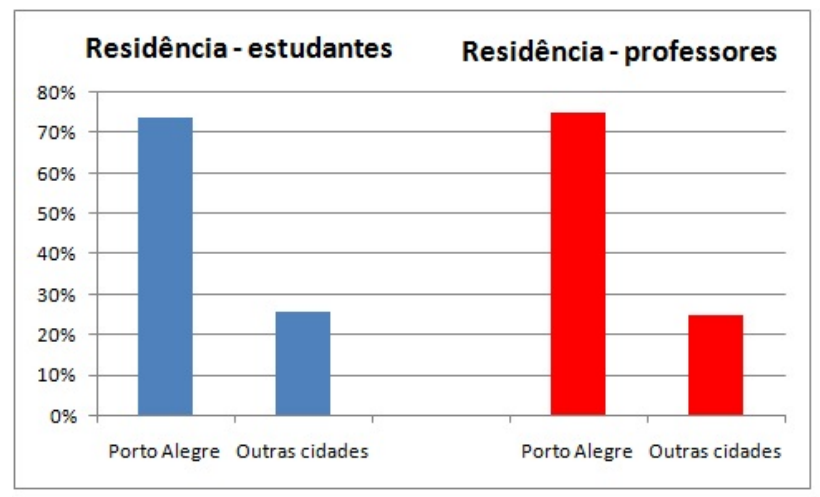

Figura 4: Gráfico - local de residência dos sujeitos

Organização: o autor (2020)

Em relação ao grupo de professores, foi possível constatar que a expressiva maioria (75\%) reside em Porto Alegre e reside em outros municípios do estado do RS o percentual de $25 \%$, mesmo realizando suas atividades laborais em Porto Alegre. É possível constatar, portanto, ao comparar os dados de residência de estudantes e professores que, mesmo sendo a maioria dos sujeitos residindo em Porto Alegre, há determinado equilibro entre tal percentual se comparados os dois grupos.

Para poder analisar as percepções sobre o racismo dos sujeitos da pesquisa, foram apresentadas as mesmas frases/afirmações para o grupo dos estudantes e para o grupo dos professores. Os sujeitos, ao registrarem seu grau de concordância, indiferença ou discordância ao observarem tais afirmações, demonstraram suas primeiras impressões acerca do tema, o que nos possibilitou analisar os sentidos imediatos dos participantes sobre o que lhes era apresentado. Após, foram construídos os gráficos comparativos, para o conjunto de respostas de cada grupo e, com isso, colocadas as informações lado a lado para a devida análise e comparação. 
A primeira afirmação apresentada aos sujeitos foi: "negros sofrem racismo todos os dias no Brasil”. A escolha por essa afirmação se deu para que se levassem em conta os dados da empiria e da convivência diária com pessoas negras. Além disso, levaram-se em conta os múltiplos dados ofertados pelo movimento negro (DOMINGUES, 2007), quando apresentam o racismo como uma realidade latente da população negra brasileira. Ao perguntar para os sujeitos da pesquisa qual era o grau de concordância (plena ou parcial), indiferença ou discordância (plena ou parcial), foi possível levantar o gráfico comparativo que segue (figura 5):

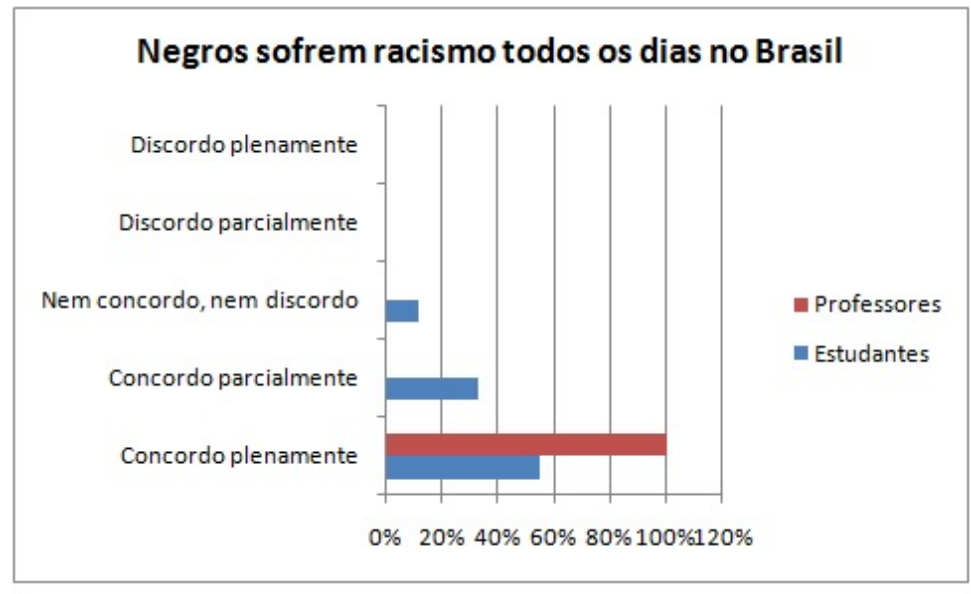

Figura 5: Gráfico - Negros sofrem racismo todos os dias no Brasil Organização: o autor (2020)

A partir da análise do gráfico, é possível verificar que a totalidade (100\%) do grupo dos sujeitos professores possui grau de concordância em relação à afirmação colocada em tela. Quanto aos dados dos sujeitos estudantes, 55\% concordam plenamente e 33\% concordam parcialmente, tendo, portanto, um somatório de $88 \%$ dos estudantes na faixa de concordância com a afirmação. Foi possível constatar, ainda, que 12\% dos estudantes encontraram-se na faixa de indiferença em relação à afirmação. Analisa-se, dessa forma, que, por mais que $88 \%$ dos estudantes encontrassem-se na faixa de concordância, ao analisar os dados de modo pontual, esse índice cai para 55\% de concordância plena, o que, comparado aos 100\% dessa variante de concordância no grupo de professores, expressa que há notável distanciamento em relação aos sentidos atribuídos na frase colocada para verificação dos sujeitos.

A segunda afirmação apresentada aos sujeitos estudantes e professores foi: "todos os negros sofrem racismo". A escolha por essa afirmação se deu ao ser possível 
proporcionar reflexão sobre a realidade social específica do Brasil, na qual se sabe que a população negra tem sido, historicamente, alvo das mais variadas manifestações de racismo. Além disso, é possível considerar os dados historiográficos apresentados pelo movimento negro (DOMINGUES, 2007), quando apresentam o racismo como uma realidade cotidiana da população negra brasileira. Ao perguntar para os sujeitos da pesquisa qual era o grau de concordância, indiferença ou discordância, foi possível construir o gráfico (figura 6) que segue:

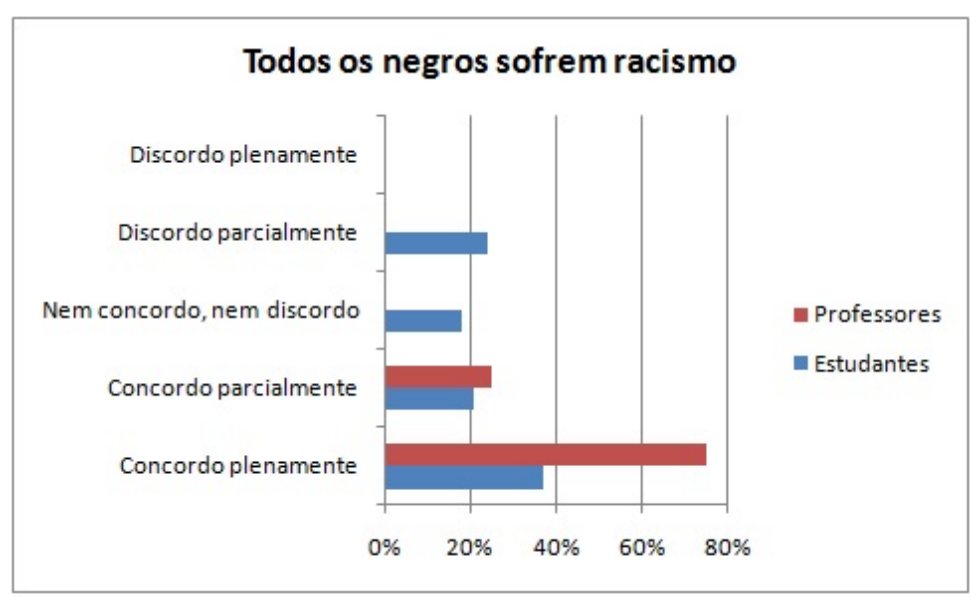

Figura 6: Gráfico - Todos os negros sofrem racismo

Organização: o autor (2020)

A partir da análise do gráfico, é possível verificar que a maioria (75\%) do grupo dos sujeitos professores possui grau de concordância plena e que $25 \%$ possuem grau de concordância parcial em relação à afirmação em evidência, ou seja, a totalidade desses sujeitos está no espectro de concordância. Quanto aos dados dos sujeitos estudantes, $37 \%$ concordam plenamente e $21 \%$ concordam parcialmente, tendo, portanto, um somatório de $58 \%$ dos estudantes na faixa de concordância com a afirmação. Foi possível constatar, ainda, que $18 \%$ dos estudantes encontraram-se na faixa de indiferença em relação à afirmação e que $24 \%$ estão na faixa de discordância (parcial) em relação ao apresentado. Verifica-se, assim sendo, que, por mais que $58 \%$ dos estudantes estivessem na faixa de concordância, ao analisar os dados de modo pontual, esse índice cai para 37\% de concordância plena, o que, comparado aos $75 \%$ dessa variante de concordância no grupo de professores, expressa que há notável distanciamento em relação aos sentidos atribuídos na frase colocada para verificação dos sujeitos. É, ainda, destacado observar que há considerável faixa (24\%) do grupo dos estudantes que está no grau de 
discordância parcial da informação por eles analisada, o que reforça tal distanciamento nessas percepções.

A terceira afirmação colocada aos sujeitos foi: "o principal alvo do racismo são negros". A escolha por essa afirmação se deu para que se levassem em conta os dados da empiria e em completude à afirmação anterior. É necessário tomar em conta os múltiplos dados ofertados pelo movimento negro e outros pesquisadores (DOMINGUES, 2007), quando apresentam o racismo como uma realidade quase que exclusiva da população negra brasileira. Ao perguntar para os sujeitos da pesquisa qual era o grau de concordância (plena ou parcial), indiferença ou discordância (plena ou parcial), foi possível montar o gráfico (figura 7) seguinte:

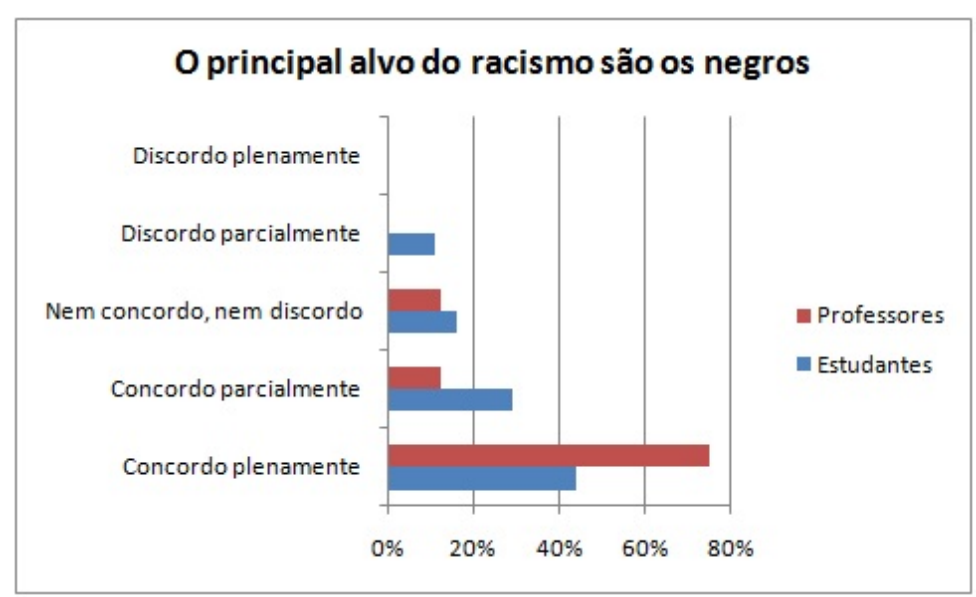

Figura 7: Gráfico - O principal alvo do racismo são os negros

Organização: o autor (2020)

A partir da interpretação do gráfico, é possível verificar que 75\% do grupo dos participantes professores possuem grau de concordância plena e que 12,5\% possuem grau de concordância parcial em relação à afirmação em questão. Ou seja, $87,5 \%$ dos professores estavam na faixa de concordância. Ainda, 12,5\% desses encontravam-se na faixa de indiferença em relação ao colocado. Quanto aos dados dos sujeitos estudantes, $44 \%$ concordam plenamente e $29 \%$ concordam parcialmente, tendo, portanto, um total de 63\% dos estudantes na faixa de concordância com a afirmação. Foi possível constatar, ainda, que $16 \%$ dos estudantes encontraram-se na faixa de indiferença e $11 \%$ na faixa de discordância (parcial) em relação à afirmação apresentada. Considera-se, portanto, que a maioria dos sujeitos professores (87,5\%) e, igualmente, a maioria dos estudantes (63\%) estão na faixa de concordância em relação ao item apresentado. Tendo em conta o índice 
apresentado, nos dois grupos, em relação à indiferença sobre o apresentado (16\% para estudantes e 12,5\% para professores) é possível considerar que a assertiva em questão possui maiores graus de proximidade do que de distanciamento, respeitadas, evidentemente, as especificidades encontradas em cada grau analisado.

A quarta afirmação apresentada aos sujeitos foi: "negros são considerados minorias na sociedade". A escolha por essa afirmação se deu para que se colocasse em debate a temática das minorias sociais, presentes em um país tão desigual quanto o Brasil. Ao perguntar para os sujeitos da pesquisa qual seriam o grau de concordância, indiferença ou discordância, elaborou-se o gráfico seguinte (figura 8):

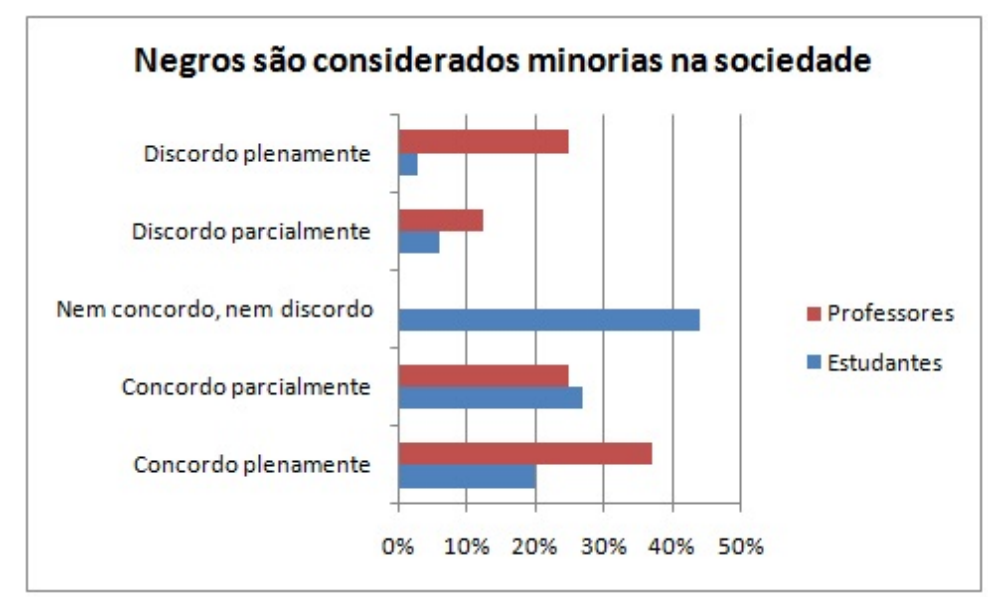

Figura 8: Gráfico - Negros são considerados minorias na sociedade Organização: o autor (2020)

A partir da observação do gráfico foi possível visualizar o quão plural apresentaram-se as respostas aos diferentes graus de concordância em relação ao proposto aos sujeitos. De maneira geral, os graus de concordância (plena ou parcial) foram: $62,5 \%$ para os professores e $47 \%$ para os estudantes. O grau de indiferença foi de $44 \%$, apenas constatado no grupo dos estudantes. Os graus de discordância (plena ou parcial), por sua vez, foram computados em $37,5 \%$ para os professores e $9 \%$ para os estudantes. É possível considerar neste tópico, portanto, que predomina certo distanciamento das percepções de estudantes e seus professores em relação ao apresentado, sobre negros serem minoria na sociedade, pois, por mais que os graus de concordância sejam maioria para os dois grupos, só foi possível verificar indiferença no grupo dos estudantes e a discordância se manifestou, em maior grau, para o grupo dos professores. 
A quinta afirmação apresentada aos sujeitos foi: "brancos praticam racismo com os negros". A opção por essa frase foi por dois motivos: o primeiro, para que se tivesse um contraponto em relação ao apresentado e discutido nas três afirmações anteriores e, posteriormente, na sexta e última afirmação, que apresentará o inverso do que foi colocado nessa assertiva. Ao questionar aos sujeitos da pesquisa qual era o grau de concordância, indiferença ou discordância, foi possível elaborar o gráfico comparativo que segue (figura 9):

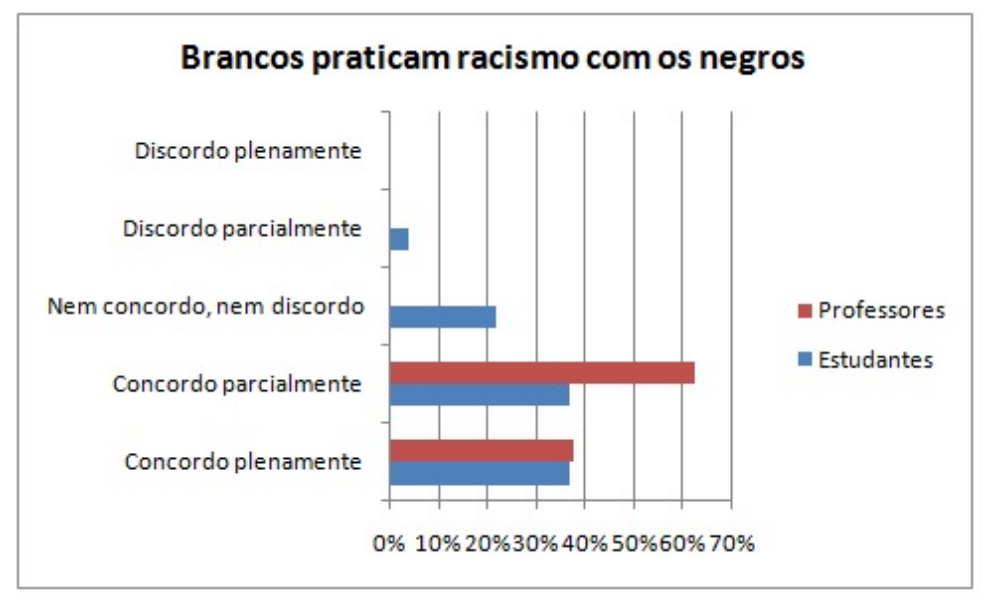

Figura 9: Gráfico - Brancos praticam racismo com os negros

Organização: o autor (2020)

A partir da análise do gráfico, é possível verificar, visualmente, que os graus de concordância, tanto para estudantes, quanto para professores, são dominantes em relação à afirmação apresentada. Nessa faixa de concordância (plena ou parcial) encontram-se $74 \%$ dos estudantes e $100 \%$ dos professores. Ainda, $22 \%$ dos estudantes estavam na faixa de indiferença, pois apontaram que nem concordavam, nem discordavam da afirmação e um número menor (4\%) discordou parcialmente da afirmação. Entende-se que há notável proximidade em relação aos sentidos atribuídos na frase colocada para verificação dos sujeitos, por mais que dados, em menor frequência, fossem constatados apenas no grupo dos estudantes.

A sexta e última afirmação disposta aos sujeitos estudantes e professores foi: "negros praticam racismo com os brancos". A escolha por essa afirmação se deu para que se pudesse construir um pensamento lógico inverso ao apresentado na afirmação anterior, uma vez que nesta afirmação, inverteram-se alvo e vítima. Se, portanto, os sujeitos, em maioria, concordavam que brancos praticam racismo com negros, segundo 
as análises da afirmação anterior, seria necessário, dessa forma, pensar o contrário. Ao perguntar para os sujeitos da pesquisa qual era o grau de concordância (plena ou parcial), indiferença ou discordância (plena ou parcial), foi possível o gráfico comparativo que segue (figura 10):

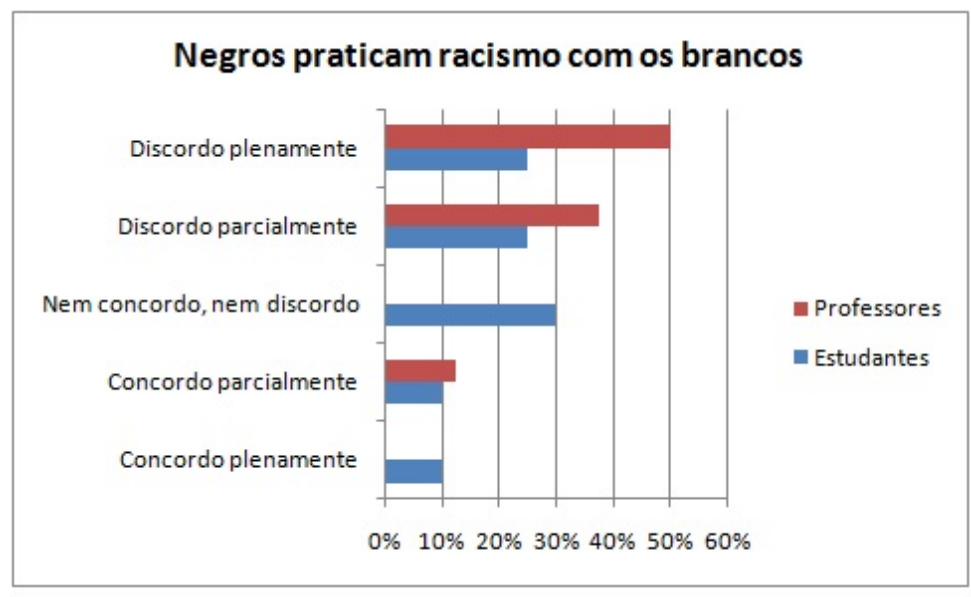

Figura 10: Gráfico - Negros praticam racismo com os brancos

Organização: o autor (2020)

E possível verificar, visualmente, que os graus de discordância, tanto para estudantes, quanto para professores, são dominantes em relação à afirmação apresentada, pela análise do gráfico. Nessa faixa de discordância (plena ou parcial) encontram-se $50 \%$ dos estudantes e $87,5 \%$ dos professores. Ainda, $30 \%$ dos estudantes estavam na faixa de indiferença, pois apontaram que nem concordavam, nem discordavam da afirmação e um número menor de estudantes (10\%) e professores $(12,5)$ concordou parcialmente da afirmação. Por fim, 10\% dos estudantes concordaram plenamente com o que Ihes foi apresentado. Na esteira do verificado na afirmação anterior, entende-se que há notável proximidade em relação aos sentidos atribuídos na frase colocada para verificação dos sujeitos, por mais que dados, em menor frequência, fossem constatados no grupo dos estudantes.

Como colocado, no final questionário do grupo dos professores foi colocada uma questão aberta sobre quais ações antirracistas eles proporcionam em suas aulas, de maneira a que se pudesse gerenciar não somente um melhor entendimento daquilo que havia sido afirmado por esses nas perguntas de escala Likert, mas que também fosse possível constatar que, cada sujeito a seu modo, vem refletindo e proporcionando espaços de aprendizagem em busca de uma educação antirracista. Nesse ponto, a 
célebre citação de Angela Davis (2020), ganha mais notoriedade, pois, efetivamente, "em uma sociedade racista, não basta não ser racista, é preciso ser antirracista”.

Assim sendo, as respostas dos sujeitos professores puderam ser distribuídas em duas categorias básicas: as ações de cunho atitudinal (que dizem respeito às atitudes individuais ou coletivas dos professores) e as ações de cunho procedimental (que dizem respeito às atitudes profissionais, relativas ao trabalho docente). A fala de um dos professores, em relação a procedimentos atitudinais foi:

S1: Procuro tratar os estudantes com respeito a partir das regras que valem para todos, além de oferecer as mesmas oportunidades de aprendizagem nas turmas com as quais trabalho.

É possível constatar o esforço desse docente na medida em que sua atitude de valorizar as regras, normativas e combinações no sentido de evitar a exclusão tanto no âmbito do desenvolvimento moral dos estudantes e das aprendizagens dos mesmos. As falas de outros sujeitos professores, em relação às ações de cunho procedimental foram:

S2: Debates quando a questão surge espontaneamente.

S3: Projetos literários com leitura de livros que abordam essas questões, debates sobre racismo, estereótipos. Discussão sobre tons de pele e o que isso significa para a sociedade. Pesquisas de personalidades negras e sua importância.

S4: Sempre incluo personalidades negras de diferentes países nas atividades que planejo. Tento resgatar com os alunos a importância do legado dessas personalidades para a sociedade.

S5: Indiretamente, tento discutir questões termos como "empatia", além de tentar mostrar como o Brasil teve uma história forjada em cima do racismo, de modo que os alunos tentem compreender a importância de falarmos sobre esse tema.

S6: Desenvolvimento da noção de interculturalidade e alteridades, para que possamos ver no diferente e no diverso uma riqueza, uma oportunidade de crescimento como pessoas e humanidade.

S7: Valorização das produções científicas e dos saberes de afrodescendentes e de diferentes etnias; intolerância a atitudes racistas; atividades integradas entre os meus estudantes e estudantes de outras etnias.

S8: Acredito que ações antirracistas precisam acontecer em todas as aulas. Toda ação preconceituosa e desrespeitosa realizada em aula precisa ser problematizada para que se transforme em uma ação de conscientização.

No caso dos professores que apontaram procedimentos (didáticos ou teóricos) foi possível perceber a diversidade de ações técnico-pedagógicas que são possíveis de serem 
oferecidas aos estudantes, às turmas e à escola como um todo. Debates, projetos literários, inclusão de personalidades negras, desconstrução da história do Brasil, desenvolvimento de interculturalidade, valorização dos saberes afro-descendentes e promoção de ações de conscientização são alguns dos exemplos apontados. O fundamental é, portanto, evidenciar o que já se faz e potencializar que novas ações antirracistas sejam realizadas.

\section{CONSIDERAÇÕES FINAIS}

Neste trabalho foi possível analisar um panorama das percepções de estudantes e professores de uma escola da rede pública de ensino, em Porto Alegre, sobre alguns elementos da temática do racismo. O principal objetivo do trabalho foi analisar as percepções de estudantes e professores sobre o racismo. Para atingir este objetivo, aplicou-se um questionário dividido em duas partes principais, a caracterização da amostra da investigação e a verificação dos graus de concordância, indiferença ou discordância em relação à de seis afirmações que apresentavam situações ou pensamentos relacionados ao racismo, as quais possibilitaram atingir os objetivos específicos da investigação.

Ao caracterizar a amostra da investigação foi possível conhecer, ainda que em apenas quatro tópicos (idade, gênero, etnia e local de residência), os sujeitos da pesquisa (estudantes e professores), a partir das informações coletadas. A caracterização da amostra de uma pesquisa permite aos pesquisadores um reconhecimento do campo e dos sujeitos, de maneira a identificar possível futuras relações com os demais campos do instrumento de coleta de dados, o questionário, no caso. Em relação à idade, a maior parte dos sujeitos estudantes era composta por participantes com 13 anos, dos sujeitos professores, a maior parte tinha entre 18 e 40 anos. Há, portanto, destacada diferença etária. Em relação ao gênero, tanto estudantes quanto professores do gênero feminino formaram maioria, com destaque para percentual mais acentuado no grupo dos professores. Em relação à etnia, a discrepância dos dados dos sujeitos foi visível e notória: enquanto encontraram-se professores autodeclarados brancos em maioria, os estudantes, em maior número, eram autodeclarados negro-pardos. Em relação ao local de residência, por fim, a maioria de estudantes e professores residia em Porto Alegre, 
sendo que, no grupo dos estudantes encontraram-se sujeitos residentes em cidades da Região Metropolitana de Porto Alegre, como Viamão, por exemplo, em maior quantidade. As proximidades e/ou distanciamentos apresentadas na caracterização da amostra da investigação podem ter contribuído, a seu modo, nas percepções sobre o racismo destacadas ao longo do texto

Ao apresentar seis frases relacionadas à temática do racismo aos sujeitos da investigação e solicitar que manifestassem seu grau de concordância, indiferença ou discordância, interessantes análises puderam ser feitas: na afirmação "negros sofrem racismo todos os dias no Brasil”, percebeu-se notável distanciamento em relação aos sentidos atribuídos na frase colocada, por parte dos grupos de sujeitos participantes. $\mathrm{Na}$ afirmação "todos os negros sofrem racismo", novamente foi possível verificar o distanciamento entre as percepções de estudantes e professores. Já na afirmação "o principal alvo do racismo são negros", foi possível considerar maiores graus de proximidade do que de distanciamento entre as percepções dos sujeitos, no sentido da concordância. Na quarta afirmação, "negros são considerados minorias na sociedade", foi possível perceber que, por mais que haja maior concordância em relação à afirmação, predomina certo distanciamento das percepções de estudantes e seus professores. Já na afirmação "brancos praticam racismo com os negros", há notável proximidade em relação aos sentidos atribuídos na frase colocada para verificação dos sujeitos, no sentido de concordar com a afirmação que lhes era proposta. Por fim, na afirmação invertida da anterior, "negros praticam racismo com os brancos", novamente verificam-se proximidades, mas, nesse caso, a partir da ótica da discordância em relação à afirmação. É possível considerar, portanto, que, a partir da amostra da presente investigação, entre estudantes e professores há mais proximidades do que distanciamentos nas percepções sobre a temática do racismo, mesmo que o número de assertivas tenho sido igualmente dividido entre proximidades e distanciamentos, a minuciosa análise individual de cada tópico leva a crer que os dois grupos caminham para uma percepção mais alinhada do que distanciada em relação ao tema.

Ao conhecer as estratégias que os professores participantes da investigação tomam, cotidianamente, em relação a práticas pedagógicas antirracistas, foi possível perceber o quanto a educação já faz em prol de uma sociedade mais justa e igualitária e, ao mesmo tempo, pode-se ter noção do quanto ainda falta a ser feito. É a partir do 
trabalho cotidiano, em cada sala de aula, que vão se formando as novas gerações, com mais capacidade de reflexão e na busca pela construção de um país no qual as diferenças étnicas não sejam motivos para a geração de preconceitos, mas sim de laços fraternos.

Conhecer as percepções sobre o racismo de estudantes e deus professores, não se configura, então, como algo importante apenas a realidade escolar estudada, mas sim para todo e qualquer professor e as outras realidades educativas do Brasil, já que as bagagens trazidas pelos estudantes devem sempre ser utilizadas como referência para partir da base já existente nos alunos e, com isso, possibilitar a exploração de novos horizontes, um milagre moderno que a educação como um todo vem realizando com todo o empenho e dedicação possíveis. Conhecer e compreender melhor o passado e o presente de um país tão rico cultural e diversamente como o Brasil possui tom de real necessidade frente aos constantes ataques que a educação e a ciência vêm sofrendo nos últimos anos e o combate ao racismo, bem como o reconhecimento dos negros enquanto parte fundante da cultura do Brasil possui grande respeito e admiração.

\section{REFERÊNCIAS}

ALMEIDA, Eduarda Soares de; OLIVEIRA, Victor Hugo Nedel. Racismo na educação: uma análise da percepção de professores. In: OLIVEIRA, Victor Hugo Nedel (org.) et al. Iniciação científica no ensino fundamental - anos finais: a pesquisa como opção metodológica. 1 ed. Mauritius: Novas Edições Acadêmicas, 2020.

BARDIN, Laurance. Análise de conteúdo. Lisboa: Edições 70, 1977.

CERQUEIRA, Daniel Ricardo de Castro; MOURA, Rodrigo Leandro de. Vidas perdidas e racismo no Brasil. Violência Urbana, v. 22, n. 10, nov. 2013.

DAVIS, Angela. Angela Davis. Disponível em: https://www.geledes.org.br/angela-davis/. Acesso em: 21 abr. 2020.

DOMINGUES, Petrônio. Movimento negro brasileiro: alguns apontamentos históricos. Tempo (UFF), v. 23, 2007.

GIL, Antônio Carlos. Métodos e técnicas de pesquisa social. São Paulo: Atlas, 2007.

GUIMARÃES, Antonio Sérgio Alfredo. Preconceito de cor e racismo no Brasil. Revista de Antropologia, São Paulo, v. 47, n. 1, 2004 
HOFBAUER, Andreas. Ações afirmativas e o debate sobre racismo no Brasil. Lua Nova Revista de Cultura e Política. São Paulo, n. 68, 2006.

JENSEN, Tina Gudrun. Discursos sobre as religiões afro-brasileiras: da desafricanização para a reafricanização. Revista de Estudos da Religião. n. 1, 2001, p. 1-21.

LIKERT, Rensis. A technique for the measurement of atitudes. Archives of Psychology, v. 140, p. 1-55, 1932.

MEDINA FILHO, Antônio Luiz de. Importância das imagens na metodologia de pesquisa em psicologia social. Psicologia e Sociedade, Belo Horizonte, v. 25, n. 2, 2013.

MINAYO, Maria Cecília de Souza. Conceito de avaliação por triangulação de métodos. In: M. C, Minayo, S. G, Assis, \& E. R, Souza (Eds), Avaliação por triangulação de métodos. Abordagem de programas sociais. Rio de Janeiro: Fiocruz, 2005. p. 19-51.

OLIVEIRA, Victor Hugo Nedel. (De) marcando a cidade: vivências urbanas de jovensestudantes do Colégio de Aplicação da UFRGS. Cadernos do Aplicação, UFRGS, v. 31, 2019, p. 71-85.

OLIVEIRA, Victor Hugo Nedel; LACERDA, Miriam Pires Corrêa de; SANTOS, Andreia Mendes dos. As percepções de Brasil de estudantes de $7^{\circ}$ ano do ensino fundamental no cenário político atual. Revista de Ensino de Geografia, v. 10, p. 52-65, 2019.

OLIVEIRA, Victor Hugo Nedel; LACERDA, Miriam Pires Corrêa de; SANTOS, Andreia Mendes dos. A construção da docência no ensino superior a partir do conceito de experiência. Cadernos do Aplicação, UFRGS, v. 32, 2020, p. 83-92.

OSINSKI, Isabel Cañadas; BRUNO, Alfonso Sánchez. Categorías de respuesta en escalas tipo Likert. Psicothema, v. 10, n. 3, 1998, p. 623-631.

PIRES, Raíssa Cordoni e Souza; OLIVEIRA, Victor Hugo Nedel. Racismo e educação: uma análise sobre a percepção de alunos. In: OLIVEIRA, Victor Hugo Nedel (org.) et al. Iniciação científica no ensino fundamental - anos finais: a pesquisa como opção metodológica. 1 ed. Mauritius: Novas Edições Acadêmicas, 2020.

PRANDI, Reginaldo. As religiões afro-brasileiras e seus seguidores. Civitas - Revista de Ciências Sociais, v. 3, n. 1, jun. 2003, p. 15-33.

SARDELICH, Maria Emilia. Leitura de imagens, cultura visual e prática educativa. Cadernos de Pesquisa, São Paulo, v. 36, n. 128, mai./ago. 2006.

SCHMIDT, Maria Auxiliadora Moreira dos Santos; GARCIA Tânia Maria F. Braga. A formação da consciência histórica de alunos e professores e o cotidiano em aulas de história. Cad. CEDES, Campinas, v. 25, n. 67, set./dez. 2005. 
SILVA, Aída Maria Monteiro. A violência na escola: a percepção dos alunos e professores. São Paulo: FDE, 1997.

TROJAN, Rose Meri; SIPRAKI, Robson. Perspectivas de estudos comparados a partir da aplicação da escala Likert de 4 pontos. Revista Ibero-Americana de Estudos em Educação, v. 10, n. 2, 2015, p. 275-300.

VIEIRA, Sonia. Como elaborar questionários. São Paulo: Atlas, 2009.

Recebido em: 22/04/2020

Parecer em: 25/06/2020

Aprovado em: 09/01/2021 